\title{
Provision of an emergency theatre in tertiary hospitals is cost-effective: Audit and cost of cancelled planned elective general surgical operations at Pietersburg Hospital, Limpopo Province, South Africa
}

\author{
M M Z U Bhuiyan, FRCSG, MMed; R Mavhungu, BSc (Med Sci); A Machowski, MD, PhD \\ Department of General Surgery, Pietersburg Hospital and Faculty of Health Sciences, University of Limpopo, South Africa
}

Corresponding author: M M Z U Bhuiyan (bhuiyanmirza@gmail.com)

Background. Cancellations of planned elective surgical operations increase financial cost to the patient and the hospital.

Objectives. To determine the rate and reasons for cancellations, estimate the cost incurred by such cancellations and recommend possible solutions.

Methods. We did a prospective descriptive study of cancellations of elective general surgical operations over the 1-year period January December 2014 in the main theatre at Pietersburg (PTB) Hospital, Limpopo Province, South Africa. All patients listed on the theatre booking slate for elective general surgical operations before the cut-off time of $13 \mathrm{~h} 00$ on the day before the anticipated operation were included. Epi Info version 7 was used to analyse the data and derive the descriptive statistics.

Results. There were 537 booked patients (median age 47 years, range 1 - 94); a total of 298 operations were performed, and 239 were cancelled (cancellation rate $44.5 \%$ ). Reasons for cancellation were as follows: theatre needed for an emergency $n=154(64.4 \%)$, theatre equipment failure and lack of consumables $n=17(7.1 \%)$, non-theatre equipment failure $n=10(4.2 \%)$, prolonged time of operations $n=13$ (5.4\%), abnormal blood results $n=8(3.3 \%)$, patient comorbidity and poor general condition $n=9(3.8 \%)$, patients absent from the ward $n=8$ (3.3\%), patients not starved $n=2(0.8 \%)$, patients' condition improved significantly $n=3(1.3 \%)$, nurses' strike $n=5(2.1 \%)$, rebooking of cases for senior surgeons or other specialty $n=2(0.8 \%)$, and other reasons $n=8(3.3 \%)$. The cost per inpatient per day was estimated at ZAR4 890 at PTB Hospital and ZAR2 100 at district hospitals, and the total cost per cancelled operation was ZAR25 860.

Conclusions. Over the 1-year period $44.5 \%$ of elective operations at PTB Hospital were cancelled, $64.4 \%$ because the theatre was needed for an emergency operation. We recommend that a theatre dedicated to emergencies be opened at PTB Hospital. The cost incurred due to cancellations was about ZAR6 million for the hospital, with additional cost and emotional trauma for the patients.

S Afr Med J 2017;107(3):239-242. DOI:10.7196/SAMJ.2017.v107i3.10687

Surgery is an 'indivisible, indispensable part of healthcare', and surgical and anaesthetic care should be an integral component of the national health system in countries at all levels of development. Five billion people worldwide do not have access to safe, affordable surgical and anaesthetic care when needed, lack of access being worst in low- and middle-income countries (LMICs), where nine out of ten people cannot access basic surgical care - 143 million additional surgical procedures are needed in LMICs each year in order to save lives and prevent disability. ${ }^{[1]}$ Thirty-three million individuals face catastrophic health expenditure due to payment for surgical and anaesthetic care each year. ${ }^{[1]}$

Cancellation of planned operations on the day of surgery is a serious problem with undesirable consequences. It results in emotional trauma and inconvenience for patients and their families, as well as the medical team. ${ }^{[2]}$ The people who suffer most are those of low income, who depend entirely on the public health services for their healthcare needs. In addition, cancellation of an operation results in wasted investigations and blood cross-matching. ${ }^{[3]}$ In some cases a delay in operation results in an undesirable clinical outcome, particularly in cancer patients, where local and distant metastases may progress. The rate of surgical cancellation is one of the most important quality indicators of operating theatre efficiency. ${ }^{[4]}$

Cancellations of scheduled elective operations are a major drain on health resources, ${ }^{[5]}$ as patients must undergo further preoperative clinical investigations when they return for the rescheduled operation. Apart from hospital inpatient costs, the government also spends a considerable amount of money on transporting patients in ambulances or planned patient transport to and from the referring hospitals. Patients are also personally financially affected because they have to take time off from work, ${ }^{[6]}$ adding to the financial burden of the low-income population.

Pietersburg (PTB) Hospital is a 500-bed tertiary hospital in Limpopo Province, South Africa (SA), serving 5.5 million people. Although it is a tertiary hospital, it also provides secondary care services because there are no regional hospitals in its district. Moreover, many hospitals in Limpopo have no surgeons. PTB Hospital is the only hospital in Limpopo that provides 24-hour services for general surgery patients. The hospital has six operating theatres catering for all surgical disciplines during the day. There was no daytime emergency theatre for surgical disciplines during the time of the study.

We could not find any literature on the actual cost analysis of cancellations of operations in SA, and specifically in Limpopo.

\section{Objectives}

(i) To determine the rate of cancellation of elective general surgical operations at PTB Hospital; (ii) to identify the causes of cancellation; (iii) to estimate the cost incurred due to cancelled operations; and (iv) to recommend possible solutions. 


\section{Methods}

This was a prospective descriptive study of cancellations of planned elective general surgical operation over the 1-year period January December 2014.

Target population. All booked patients (adults and children) for elective operations in general surgery were enrolled.

Inclusion criteria. All patients listed on the theatre booking slate for elective general surgical operations before the cut-off time of $13 \mathrm{~h} 00$ a day before the anticipated operation were included.

Exclusion criteria. Patients booked in the diary but not on the list for the operation the following day because of reasons identified before preparation of the list (e.g. theatre table broken, anaesthetic machine not working, power failure) were excluded.

A pre-designed data collection sheet was used to collect the information. The documented variables were: patient's initials, hospital number, age, gender, ward, surgeon, procedure, cancellation and reason for cancellation. The categories for reasons for cancellation were decided on after data collection. A database was created in Excel 2010 (Microsoft, USA) and the collected information was captured into this database. Categorical data were displayed as percentages, while continuous data were reported as medians and ranges. Epi Info version 7 (Centers for Disease Control and Prevention, USA) was used for data analysis.

\section{Cost}

The cost of inpatient stay was estimated from the document of the Annual Performance Plan, Department of Health, Limpopo Provincial Government, SA, dated 4 March 2015 (unpublished) and the District Health Information System for PTB Hospital for the 2014/15 financial year (unpublished). The cost per patient per day, which is called the patient-day equivalent (PDE), was calculated as:

$\mathrm{PDE}=[$ Sum of inpatient day total $+($ day patient total $) \times 0.5+$ $($ OPD patient total + emergency head count total $) \times 0.333] /$ total expenditure in 1 year

The PDE was estimated at ZAR4 890 for PTB Hospital and ZAR2 100 for district hospitals. This implies a cost of ZAR19 560 per patient for 4 days in PTB Hospital waiting for the operation, and ZAR6 300 per patient for 3 days in district hospitals.

\section{Results}

Over the 1-year period, 537 elective general surgical operations were booked; 298 of these were performed and 239 were cancelled, giving a cancellation rate of $44.5 \%$. The age range of the study group was 1 - 94 years (median 47). The elective operations booked are listed in Table 1 and the reasons for cancellation in Table 2.

The PDE was estimated at ZAR4 890 at PTB Hospital and ZAR2 100 at district hospitals ${ }^{[7]}$ (Table 3).

\section{Discussion}

The cancellation rate in our study was $44.5 \%$, compared with the generally acceptable cancellation rate of $<5 \%$ for efficient operating theatres. ${ }^{[7]}$ The high rate of cancellations in our institution is unique considering the unusual setting of our hospital. Cancellation rates and reasons vary between different hospital types and sizes, reported rates ranging from $5.6 \%$ to $25 \%{ }^{[4,8-9]}$ Eight percent of scheduled operations are cancelled in the UK. ${ }^{[10]}$ The most common reason for cancellation in our study (64.4\%) was the addition of emergency cases to elective lists, which seriously interrupted the schedule of elective procedures. A study by Biccard et al. ${ }^{[11]}$ showed that $54.2 \%$ of operations done in SA are urgent or emergency. PTB Hospital
Table 1. Operations booked

\begin{tabular}{ll}
\hline Procedure & $\boldsymbol{n}$ \\
\hline Hernia repair & 99 \\
Amputation & 88 \\
Lump/mass excision & 59 \\
Mastectomy and breast lump excision & 53 \\
Colostomy closure and diverting colostomy & 38 \\
Repair/creation of arteriovenous fistula & 31 \\
Thyroidectomy & 27 \\
Wound debridement & 23 \\
Cholecystectomy & 20 \\
Skin graft & 12 \\
Aneurysm & 8 \\
Gastrostomy & 8 \\
Hemicolectomy - colon cancer & 6 \\
Sigmoidectomy & 5 \\
Other (fissurectomy, haemorrhoidectomy, excision of & 60 \\
perineal warts, etc.) & \\
Total & 537
\end{tabular}

had no separate theatre dedicated to emergency cases during the daytime throughout the study period. When emergencies arrived, the practice was to replace an elective booking with the emergency case. Other tertiary hospitals around the world have emergency theatres. ${ }^{[3,9]}$ There is always a backlog of patients waiting for theatre in a tertiary hospital, and in our department the waiting period for operations is 6 - 10 months.

The second most common reason for cancellation was theatre equipment failure or lack of consumables (7.1\%). Cancellations due to prolonged duration of earlier operations accounted for $5.4 \%$. Estimation of procedure times when preparing operation lists is an important factor in avoiding unnecessary cancellations.

Non-theatre equipment failure (most commonly shortage of linen) was another reason for cancellations in our study, and could be avoided if appropriate measures are taken timeously. ${ }^{[4]}$

Comorbidity and poor general condition of the patient contributed to $3.8 \%$ of cancellations in our study, and eight patients (3.3\%) could not be operated on because of abnormal blood results. This group of patients needed further work-up to improve their condition before surgery. Preoperative anaesthetic assessment is very important and significantly reduces cancellation rates. ${ }^{[12]}$

Another important factor, resulting in $3.3 \%$ of cancellations in our study, was patients being absent from the ward. Possible explanations for this could be poor communication between patient and healthcare providers, improvement in the patient's condition, or death of the patient before the scheduled operation date owing to a long waiting list. In a study by Basson et al. ${ }^{[13]}$ non-appearance of patients accounted for one-third of cancellations. Patients should not be placed on a theatre list if they are not in the ward by $12 \mathrm{~h} 00$ on the day before the operation; instead, the space should be allocated to another patient who is already in the hospital.

Two percent of scheduled cases were cancelled because of a nurses' strike. Strike conditions have been found to reduce the quality of service delivery, particularly with regard to elective operations. ${ }^{[14]}$ Strikes can be avoided by improved communication between the administration and striking personnel. Another 
Table 2. Reasons for cancellation on the day of surgery $(N=239)$

\begin{tabular}{lll}
\hline Reason & $n(\%)$ & Comments \\
\hline $\begin{array}{l}\text { Emergency booking } \\
\text { Theatre equipment failure or no consumables }\end{array}$ & $154(64.4)$ & \\
$\begin{array}{ll}\text { Prolonged time of operations } \\
\text { Non-theatre equipment failure }\end{array}$ & $13(5.4)$ & $\begin{array}{l}\text { No endotracheal tubes, no mesh, anaesthetic machine failure, } \\
\text { broken theatre table }\end{array}$ \\
Comorbidity, poor general condition & $10(4.2)$ & No water or linen, lift not working, power failure \\
Blood results abnormal & $9(3.8)$ & $\begin{array}{l}\text { Patient not fit for operation, needed blood transfusion or other } \\
\text { reasons }\end{array}$ \\
$\begin{array}{l}\text { Patient not in the ward } \\
\text { Nurses' strike }\end{array}$ & $8(3.3)$ & \\
Operation not needed & $8(3.3)$ & \\
Rebooked for senior surgeon or other specialty & $5(2.1)$ & Patient's condition improved significantly \\
Patient not starved & $3(1.3)$ & Patient's condition complicated \\
Other reasons & $2(0.8)$ & Patient refused operation, patient died before operation, no \\
& $8(3.3)$ & nursing staff, no blood results
\end{tabular}

Table 3. Patient costs (inpatient hospital stay, excluding transport)

\begin{tabular}{|c|c|c|c|c|c|}
\hline & Hospital & Days & Cost per day (ZAR) & Total cost per patient (ZAR) & Total cost (ZAR) \\
\hline \multirow{2}{*}{$\begin{array}{l}\text { Hospital cost } \\
\text { (inpatient stay) }\end{array}$} & РTB & 4 & 4890 & 19560 & 25860 \\
\hline & District hospitals & 3 & 2100 & 6300 & \\
\hline $\begin{array}{l}\text { Sub-total (per single } \\
\text { patient) }\end{array}$ & & & & & 25860 \\
\hline $\begin{array}{l}\text { Total }(N=231 \\
\text { patients })\end{array}$ & & & & & 5973660 \\
\hline
\end{tabular}

unfortunate cause of postponement of operations, accounting for two cases in our study, was that the patient was not starved.

Cancellation of elective surgical operations is a major concern that is not only disruptive to both health personnel and patients, but also contributes to loss of hospital income. Operating rooms generate revenue for the hospital. Theatre equipment is expensive, and its proper utilisation is therefore of the utmost importance. Ideally a cancelled procedure should be rebooked for the following day, but such rescheduling is difficult at PTB Hospital because each firm in the department is allocated one theatre day per week. Most patients were discharged and given another date between 2 and 4 months later, depending on theatre space availability. Some semi-urgent cases, such as gangrene of the foot, were operated on after hours or over the weekends as an emergency.

Many of our discharged patients in Limpopo do not go straight home, instead being sent back to their referral hospitals. Patients usually wait about 2 days after cancellations to enable transport back to the peripheral hospitals to be arranged. On arrival at the peripheral hospital, the patient stays overnight and is only discharged the following day. On average, cancelled patients spend 4 days in PTB Hospital and 2 - 3 days in a peripheral hospital ( 1 - 2 days before patients are transported to PTB hospital and 1 day after they are sent back from PTB Hospital).

In our study the PDE was estimated to be ZAR4 890 for PTB Hospital and ZAR2 100 for district hospitals. This implies a cost of ZAR19 560 per patient for the 4 days in PTB Hospital waiting for the operation, and another ZAR6 300 per patient for the 3 days at the district hospital. The total cost to the health authority per single cancelled operation was estimated at ZAR25 860. The cost of 231 cancellations of general surgical operations (239 minus the eight cancelled because the patient was not in the hospital) recorded during 2014 therefore totalled nearly ZAR6 million. In addition to the above inpatient costs, travelling costs were incurred by the emergency medical service or planned patient transport, but we did not include these in the study.

One hundred and fifty-four elective operations were cancelled in 2014 because the theatre was needed for an emergency operation. This implies that if the hospital had had an emergency theatre, a substantial amount of money could have been saved, and in addition extra revenue could have been collected from the operations that no longer had to be cancelled. Running an additional theatre for emergency cases during the daytime would require one medical officer (anaesthetist) and three nursing staff. A medical officer (grade 2 salary notch) earns ZAR634 269 per annum and a nurse a maximum of ZAR227 802 (ZAR683 406 for three nurses). The total staff cost for one additional theatre for emergency operations during the day would therefore be ZAR1 317675 per year.

With a cost of ZAR25 860 per single cancellation, and 154 elective cancellations in 2014 due to emergency bookings, totalling nearly ZAR4 million, the hospital could have saved ZAR2.7 million (ZAR4 million less the ZAR1.3 million staff cost) if there had been an emergency theatre. This calculation relates only to cancelled elective 
general surgical operations; if cancellations of operations from other surgical departments were to be included, the amount would probably be higher.

Cancellations have very serious negative consequences and huge financial implications for both patients and hospitals. This is especially important in developing countries that face severe budgetary constraints and where resources should therefore be managed with the utmost efficiency. The cancellation of operations is very costly and must be avoided and kept below $5 \% \cdot{ }^{[9]}$ Other key factors, such as availability of water and electricity and an adequate supply of clean linen, are also important in the effort to reduce cancellations.

Investment in appropriate resources for the provision of surgical services is affordable, saves lives, and will promote economic growth. ${ }^{[1]}$

\section{Study limitations}

Our study did not include a record of the commencing time and duration of operations, which might have detected poor time management, e.g. late starting of operations and long tea or lunch breaks. Information was collected for general surgical patients only. The study did not include costs related to transportation of patients whose operations were cancelled.

\section{Conclusions}

- Over a 1-year period at PTB Hospital the rate of cancellation of elective operations was $44.5 \%$, with more than half (64.4\%) due to emergency operations.

- The total financial loss to the hospital as a result of cancellations was $\sim$ ZAR6 million in 2014.

- Financial costs and emotional trauma for the patients and their relatives could be reduced by lowering the rate of cancellations.

\section{Recommendations}

- We recommend that a theatre dedicated to emergency procedures be opened.

- Any cancelled elective patient who still requires surgery should be operated on the following day as an urgent case, which will prevent a loss of ZAR25 860.
- Patients must be well prepared for their operations, and theatre consumables must be checked properly before elective operations are booked.

- Most of the work done at PTB hospital should be done at appropriately staffed district and regional hospitals.

Acknowledgements. We are grateful to Mr Joseph Wamukuo and Dr F L M Hyera for their valuable comments on this article.

1. Meara JG, Leather AJM, Hagander L, et al. Global Surgery 2030: Evidence and solutions for achieving heath, welfare and economic development. Lancet 2015;386(9993):569-624. http://dx.doi.org/10.1016/ S0140-6736(15)60160-X

2. Tait AR, Voepel-Lewis T, Munro HM, Reynolds PI. Cancellation of pediatric outpatient surgery: Economic and emotional implications for patients and their families. J Clin Anesth 1997;9(3):213-219. http://dx.doi.org/10.1016/s0952-8180(97)00032-9

3. Chiu CH, Lee A, Chiu PT. Cancellation of elective operations on the day of intended surgery in a Hong Kong hospital: Point prevalence and reasons. Hong Kong Med J 2012;18(1):5-10.

4. Huda F. A retrospective analysis of reasons for cancellations of elective surgery in a teaching hospital. Int J Sci Stud 2014;2(2):28-30.

5. Elrahman AA, Hamza AA, El-Haj MA. Cancellation of elective general surgical operations at the day of intended surgery. Glob J Hum Soc Sci: I Surgeries Cardiovasc Syst 2014;14(3):39-43. https:// medicalresearchjournal.org/index.php/GJMR/article/viewFile/676/593 (accessed 3 February 2017).

6. Vinukondaiah K, Ananthakrishnan N, Ravishankar M. Audit of operation theatre utilization in general Vinukondaiah K, Ananthakrishnan N, Ravish

7. Macrgery. Natl Med J India 2000;13(3):118-121.
7. Are your hospital operating rooms 'efficient'? A scoring system with eight performance indicators. Anesthesiology 2006;105(2):237-240.

8. Chamisa I. Why is surgery cancelled? A retrospective evaluation. S Afr J Surg 2008;46(3):79-81.

9. Zafar A, Mufti TS, Griffin S, Ahmed S, Ansari JA. Cancelled elective general surgical operations in Ayub Teaching Hospital. J Ayub Med Coll Abbottabad 2007;19(3):64-66.

10. Sanjay P, Dodds A, Miller E, Arumugam PJ, Woodward A. Cancelled elective operation: An observational study from a district general hospital. J Health Organ Manag 2007;21(1):54-58. http:// dx.doi.org/10.1108/14777260710732268

11. Biccard BM, Madiba TE, on behalf of the South African Surgical Outcomes Study investigators. The South African Surgical Outcomes Study: A 7-day prospective observational cohort study. S Afr Med J 2015;105(6):465-475. http://dx.doi.org/10.7196/SAMJ.9435

12. Ferschl MB, Tung A, Sweitzer B, Huo D, Glick DB. Preoperative clinic visits reduce operating room cancellations and delays. Anesthesiology 2005;103(4):855-859. http://dx.doi.org/10.1097/00000542200510000-00025

13. Basson MD, Butler TW, Verma H. Predicting patient nonappearance for surgery as a scheduling strategy to optimize operating room utilization in a Veterans' Administration hospital. Anesthesiology
stating 2006;104(4):826-834. http://dx.doi.org/10.1097/00000542-200604000-00029

14. Bhuiyan MMZU, Machowski A. Impact of 20-day strike in Polokwane Hospital (18 August - 6 September 2010). S Afr Med J 2012;102(9):755-756. http://dx.doi.org/10.7196/SAMJ.6045

Accepted 14 November 2016. 